\title{
A reappraisal of the impact of dairy foods and milk fat on cardiovascular disease risk
}

\author{
J. Bruce German · Robert A. Gibson · Ronald M. Krauss · Paul Nestel • \\ Benoît Lamarche · Wija A. van Staveren · Jan M. Steijns · Lisette C. P. G. M. de Groot • \\ Adam L. Lock · Frédéric Destaillats
}

Received: 31 August 2008/Accepted: 26 January 2009/Published online: 4 March 2009

(C) The Author(s) 2009. This article is published with open access at Springerlink.com

\begin{abstract}
Background This review provides a reappraisal of the potential effects of dairy foods, including dairy fats, on cardiovascular disease (CVD)/coronary heart disease (CHD) risk. Commodities and foods containing saturated fats are of particular focus as current public dietary
\end{abstract}

W. A. van Staveren - L. C. P. G. M. de Groot

Wageningen University and Research Centre, Wageningen,

The Netherlands

B. Lamarche

Institute of Nutraceuticals and Functional Foods,

Laval University, Quebec, Canada

F. Destaillats

Nestlé Research Center, 1000 Lausanne 26, Switzerland

\author{
A. L. Lock \\ Department of Animal Science, \\ University of Vermont, Burlington, VT 05405, USA \\ J. B. German ( $\square)$ \\ Department of Food Science and Technology, \\ University of California, Davis, CA 95616, USA \\ e-mail: jbgerman@ucdavis.edu \\ P. Nestel \\ Baker Heart and Diabetes Research Institute, Melbourne, \\ VIC 8008, Australia
}

\section{R. A. Gibson}

Functional Food Science, University of Adelaide, Adelaide,

South Australia 5000, Australia

J. M. Steijns

Campina Innovation, Wageningen, The Netherlands

R. M. Krauss

Children's Hospital Oakland Research Institute,

University of California, Berkeley, CA 94609, USA recommendations are directed toward reducing the intake of saturated fats as a means to improve the overall health of the population. A conference of scientists from different perspectives of dietary fat and health was convened in order to consider the scientific basis for these recommendations.

Aims This review and summary of the conference focus on four key areas related to the biology of dairy foods and fats and their potential impact on human health: (a) the effect of dairy foods on CVD in prospective cohort studies; (b) the impact of dairy fat on plasma lipid risk factors for CVD; (c) the effects of dairy fat on non-lipid risk factors for CVD; and (d) the role of dairy products as essential contributors of micronutrients in reference food patterns for the elderly.

Conclusions Despite the contribution of dairy products to the saturated fatty acid composition of the diet, and given the diversity of dairy foods of widely differing composition, there is no clear evidence that dairy food consumption is consistently associated with a higher risk of CVD. Thus, recommendations to reduce dairy food consumption irrespective of the nature of the dairy product should be made with caution.

Keywords Milk fat - Cardiovascular disease risk . Saturated fatty acid

\section{Introduction}

Public dietary recommendations for suggested intakes of macronutrients have targeted lowering total fat-specifically cholesterol, saturated fat and trans fat-intake as a means to improve the overall health of the population. These recommendations have been based on the 
assumption that saturated fat intake is associated with risk of the accelerated development of artery disease and premature mortality from heart attack and stroke. These broad recommendations to lower intake of fat have been translated by the food industry into a long-term objective of diminishing these components from agricultural commodities and foods. Industrial food processing has been acting on this objective over many years to diminish fats, particularly saturated and industrially produced trans fats, in foods. Altering fat can have important consequences to overall diet. Dramatic alterations in consumption of dairy products, because of their nutrient density, carry much more impact on public health than do just the intakes of total fat, saturated fat and cholesterol. Hence, it is appropriate to ask whether the scientific evidence in support of this basic conclusion is complete and further to ask if the implications of these recommendations, if brought to practice, are consistent with overall health of the population. A conference of scientists from different perspectives of dietary fat and health was convened to examine the complexity of dairy fat in relation to cardiovascular disease (CVD) risk in the background of currently available literature, to identify gaps in knowledge and to put dairy fat into the context of overall health. On average, bovine milk contains about $33 \mathrm{~g}$ total lipid (fat) per liter. Triacylglycerols, which account for about $95 \%$ of the lipid fraction, are composed of fatty acids of different length (4-24 C atoms), degree of saturation and positional specificity on the glycerol backbone. Other milk lipids are diacylglycerol (about $2 \%$ of the lipid fraction), cholesterol (less than $0.5 \%$ ), phospholipids (about $1 \%$ ) and free fatty acids (less than $0.5 \%$ of total milk lipids). Milk fat is present as complex globules with structural properties distinct from other biological sources of fats. Finally, there is a variety of phospholipids derived from the mammary plasma membrane around each milk fat globule. A diversity of dairy foods of widely differing composition is processed from this unique raw material. This conference was convened to examine the scientific evidence for the effects of dairy product consumption and milk lipids in human diets on overall health and the risk of CVD, the main forms of which are coronary heart disease (CHD) and stroke.

\section{The effect of dairy foods on CHD: a review of prospective cohort studies}

Diets containing dairy fats are thought to contribute to CVD/CHD primarily by increasing saturated fat intake and as a result, many advisory bodies recommend avoiding high-fat dairy foods as part of a healthy diet [4, 21, 29]. The rationale for the association between dairy fat consumption and CVD is that saturated fats increase plasma cholesterol [66], which in turn is associated with increased CVD [41]. There are conflicting data concerning the simple relationship between dairy consumption and blood lipids due in part to the complex composition of fatty acids [64, 115]. Dairy foods improve other CVD risk factors. Dairy products are also rich in calcium, and two separate metaanalyses reported an inverse relationship between higher calcium intake and reduced blood pressure [3, 22]. Data from large cohort studies may represent a wider range of characteristics and level of exposure in a community setting rather than the controlled environment of a randomized trial. Hence, the aim of this section is to review the relationship between dairy food consumption and death from CVD/ischemic heart disease using data from prospective cohort studies.

A review was undertaken to investigate the effect of dairy consumption on CVD using prospective cohort studies. A systematic search of electronic databases identified studies relating dairy food intake in adulthood to episodes or death from CVD, ischemic heart disease and myocardial infarction. Included studies were assessed for quality based on study methodology, validity of dietary assessment, success of follow-up, standardized assessment of CVD, ischemic heart disease, or myocardial infarction endpoints and appropriateness of statistical adjustment. Data from 12 cohorts involving $>280,000$ subjects were included. Most studies had follow-up of $>80 \%$, adjusted statistically for three or more confounders, and used standard criteria to determine endpoints. About half the studies used a validated food frequency questionnaire, administered the questionnaire more than once, or had a follow-up $>20$ years. Fewer than half the studies involved subject's representative of the general population. Overall findings showed 7 of the 12 cohorts found no association between dairy intake and CVD. Three cohorts reported positive relationships between dairy foods and CVD. One cohort reported a positive relationship between CVD and butter, but a negative relationship with cheese. Mixed findings from another cohort suggested no association between dairy and CVD, but showed a positive relationship with dairy protein in subsequent follow-up.

Nearly all studies reviewed used statistical analysis methods including logistic regression using Cox-regression analysis or a proportional hazard models to adjust for confounders [2, 20, 33, 39, 47, 62, 74, 92, 95, 106, 108]. The number and type of potential confounders used for statistical adjustment varied among studies, with most including age, smoking, social class and gender (when both genders were included). One study used a simple analysis of linear correlation, which does not adjust for confounders [65]. This review revealed no consistent findings to support the concept that dairy food 
consumption is associated with a higher risk of CHD. While there is no doubt that dairy foods contribute to the intake of saturated fats [47], and an excess of saturated fat intake has previously been associated with higher incidence of $\mathrm{CHD}$, the evidence extracted from these 12 prospective cohort studies does not consistently demonstrate a direct relationship between the intake of dairy foods and the risk of CVD.

\section{Are dairy foods protective?}

The current recommendations by health authorities and governments to eat low-fat dairy in preference to highfat dairy foods was supported by the data published in 1999 from the Nurses Health Study [47], as this was the only study included to examine high- versus low-fat dairy foods. In this large study, the ratio of high-fat to low-fat dairy food consumption was positively associated with an increased risk of CHD [47], even though separate analyses of high-fat or low-fat dairy food intake was not significantly associated with CHD. The most prominent relationship was between the intake of saturated fatty acids-particularly palmitic (16:0) acid—and risk of CHD. Dairy foods contributed to the intake of $15 \%$ of the total dietary saturated fatty acids and $10 \%$ to 16:0 and 18:0 (stearic) acid. Beef consumption accounted for $23 \%$ of the total saturated fat intake, highlighting the difficulty in ascribing a causal outcome to a single food group. Overall, the data from large observational studies that demonstrated good follow-up used validated questionnaires examining multiple dairy foods and conducted appropriate statistical analyses offer important insight into the association between dairy foods and CHD [2, 20, 47, 62, 106, 108]. However, the disparate findings from the present review suggests that the association between saturated fat intake from dairy foods and CHD may be weaker than expected by examining the relationship between national food data sheets and CHD mortality rates [70, 91]. This is not surprising as studies investigating national food data are unable to adequately address the confounding influences of lifestyle variables. Of the 12 studies included in the review, 8 were set-up during or before the 1970s when whole milk was the only type of milk available. Skim and lowfat milk were introduced in the 1980s. Hence, the results of early studies may relate to the consumption of highfat dairy products as low-fat alternatives only became available in the latter part of these studies. Disparity may also be a result of the specific dairy foods examined by each study and their relationship with CVD. There is some preliminary evidence that particular dairy foods may have differential effects of risk factors for
CVD. For example, in a controlled setting, cheese may have a milder effect on blood cholesterol levels than a similar quantity of dairy fats from butter. Although fermented dairy foods have been associated with a mild reduction in cholesterol in some but not in other studies [1], no studies included in the review specifically evaluated the relationship between fermented dairy foods and CVD.

\section{Effects of dairy fat on plasma lipid risk factors for CVD}

Several decades of scientific investigations have established that elevated levels of LDL cholesterol (LDL-C) are predictive of an increased risk of CVD. This association and its apparent responsiveness to diet and lifestyle, though obtained independently, are the basis for a variety of population-based interventions spanning from dietary guidelines to the Cholesterol Education Program in the US. However, in the last decade, it has become increasingly clear that while high LDL-C levels are an indication of heart disease risk, the risk of heart disease and overall morbidity and mortality are also related to low levels of the other major cholesterol carrier in blood-HDL. The epidemiologic association between low levels of HDL and increased risk and, alternatively, high levels of HDL and protection from a variety of diseases-including heart disease, infections and inflammation-has been established. Intensive research has begun to focus on this reciprocal relationship between LDL and HDL. Higher plasma concentrations of LDL-C, its respective apolipoprotein $\mathrm{B}(\mathrm{ApoB})$ and specifically the smaller, dense LDL particles, higher plasma triacylglycerol concentrations and low plasma HDL-cholesterol (HDL-C) are associated with increased risk of heart disease. Alternatively, decreased risk is associated with higher concentrations of HDL-C and its apoprotein, apolipoprotein A-I (Apo A-I), and with greater size and buoyancy of HDL subtypes [103]. Promoting HDL-C is now emerging as an important target for lowering the risk of CVD in the population. In order to capture the value of diet as an independent effector of HDL and its benefits to health by raising HDL, studies should begin to separate the effects of dietary intakes on HDL and measure the effects on different lipoprotein metabolites [15]. The benefits of HDL extend across age groups and health outcomes. For example, in a population of centenarians, a decrease in cognitive function was associated with lower HDL-C [27]. The offspring of individuals with high HDL-C had a $23 \%$ lower risk of hypertension, $50 \%$ lower risk of diabetes mellitus, a $60 \%$ lower risk of heart attacks and had no reported strokes compared with their age-matched controls [12]. 


\section{Milk fat and LDL}

Effects of individual fatty acids on LDL

Metabolic studies of the effects of individual fatty acids have shown that most saturated fatty acids, with the exception of stearic and short-chain fatty acids, raise LDLC significantly [115]. However, the effects of specific fatty acids vary. In some studies, 16:0 was the major dairy fatty acid, and it appeared to raise LDL-C to the greatest extent [75]; in other studies, lauric (12:0) and myristic (14:0) acids were the fatty acids most effective at raising LDL-C [66]. Several meta-analyses of published trials highlight these relationships and provide equations in which their LDL-C-raising effect is quantified [68]. On the other hand, cross-sectional studies that have estimated dairy fat consumption from characteristic fatty acids in plasma lipids have failed to find that the levels of such fatty acids were necessarily related to higher LDL-C levels [90]. One study suggested that the nature of the LDL particles might even be more favorable from a cardiovascular perspective in subjects with higher levels of typical dairy fatty acids; most notably, dairy fats raise solely the large and less atherogenic subpopulation of LDL particles [93]. Such findings are consistent with the conclusion that simple measures of total LDL-C are not as predictive of overall cardiovascular risk as are detailed analyses of LDL subpopulations. The positional specificity of the fatty acids in the triacylglycerol molecule may be relevant to the effects of individual fatty acids on CVD. In milk triacylglycerols, 16:0 occupies the sn-2 position, which is generally occupied by unsaturated fatty acids in plants. This unique position of 16:0 ensures that calcium in milk is highly absorbable by avoiding the formation of insoluble calcium soaps in the intestine. Because pancreatic lipase in the gut selectively hydrolyzes triglycerides at the sn- 1 and sn-3 positions, free fatty acids and 2-monoglycerides are produced. Free palmitic acid, but not 2-monopalmitin (which is efficiently absorbed), may be lost as a calcium-fatty acid soap in the feces. The debate about trans fats has largely bypassed ruminant trans fatty acids (TFA); but recently, two reports that compared ruminant TFA with industrial TFA showed that both sources of TFA (despite different mixtures of TFA) raised LDL-C similarly [25, 71]. However, as noted, the daily consumption of ruminant TFA cannot reach the amounts tested in these studies. For example, the high dose of TFA from ruminants tested in one of the two studies $(3.6 \%$ of daily energy) [71] would correspond to daily consumption of 10 servings of cheese, 5 servings of whole milk, 2 servings of full-fat yogurt and 20 teaspoons of butter. The long-term effect of even small amounts of TFA from any source is the basis of ongoing research. Conjugated linoleic acid, a small component of dairy fats, is a trans fatty acid that is unlike other trans fatty acids in its biological effects. The effects on plasma lipids of conjugated linoleic acid have been generally disappointing in human clinical trials compared with animal studies. When enriched in dairy fats, the major isomer, cis-9, trans-11 conjugated linoleic acid, has failed to lower LDL-C when consumed in amounts exceeding that currently present in dairy foods [104].

Effects of fermented versus non-fermented dairy foods on LDL

Interest in the possibility that fermented foods, including dairy foods, may confer health benefits has been long standing and may be on the increase. It is likely that milk fat alone may not be sufficient to induce adverse effects on plasma lipids, such effects being modified by other factors in specific dairy foods. The epidemiology relating to total dairy consumption or that measured as milk consumption has been interpreted differently in different publications. Although at least one large meta-analysis of prospective studies failed to find a significant association between cardiovascular events and milk consumption [34], in ecological, observational studies a positive relationship between dairy intake and heart disease has been reported [7, 34]. Of interest, however, is that two large analyses of the association between dairy fat consumption and CHD mortality-both finding the association to be positivenoted that cheese intake was exceptional in being not unfavorable [7, 87]. A specific analysis of the effects of eating cheese on CHD has not been reported, although in one analysis, there was a negative trend between CHD and cheese consumption whereas the association with milk was positive [70]. Three recently published trials comparing the influence on plasma lipids of different dairy foods at similar intakes of dairy fat suggest that eating hard cheese has a lesser LDL-C-raising effect than that of butter or milk $[17,76,101]$. Although differing in design and indeed in the type of cheese tested, the concordance of the conclusions is striking. The mechanism is uncertain; fermentation of milk and the potential hydrolysis of lipids and proteins may be one factor, the lipids are physically in different states and potential protective compounds or structures such as calcium or phospholipids may be removed during the production of butter. There are studies in which fermented dairy foods appeared to lower plasma cholesterol when compared with the non-fermented products. This has been more suggestive with yoghurts, although the nature of the microflora and their capacity to survive and colonize the gut have been major variables. Other studies have failed to show lowering of LDL-C by fermented dairy foods. The overall conclusions in reviews of the subject concede that the case for plasma cholesterol reduction with fermented dairy foods still requires proof $[98,100]$. 


\section{Milk fat and HDL}

One of the established properties of milk fat relative to polyunsaturated oils is the increase in concentration of HDL in plasma [44, 67, 93]. It is recognized from clinical, mechanistic and epidemiologic studies that HDL-C levels are an independent predictor of heart disease. Substantial epidemiological research has shown negative associations of HDL-C and heart disease-high HDL-C is associated with protection from heart disease, even in the face of elevated LDL-C, and low HDL-C is associated with increased risk, with or without elevated triglycerides. However, it has not been possible to assign independent variables to HDL-C differences, and studies have largely been based on HDL-C levels that are presumably high or low based on genetic rather than dietary determinants [78, 111, 113]. HDL are thought to exert beneficial effects on overall health by separate mechanisms, including reverse cholesterol transport and also, binding and eliminating toxins, delivering bioactive compounds, protecting various cells and lipoproteins from damage and participating in their repair $[6,11$, 24, 84, 112]. The bacterial toxin lipopolysaccharide is associated with plasma lipoproteins, suggesting that its sequestration by lipid particles may form an integral part of a humoral detoxification mechanism [35, 59, 60, 81, 109]. HDL inhibit the oxidation of LDL via the paraoxonase enzyme activity bound to HDL, and HDL are also capable of removing oxidized lipids directly from LDL [73]. The ability of HDL to protect LDL from oxidation would be expected to improve the early stages of development of LDL-laden macrophages within the artery wall and also to inhibit later stage inflammation and plaque rupture [99].

\section{Replacement of saturated fat by carbohydrates: effects on plasma lipid risk factors for CVD}

Early dietary interventions sought to demonstrate a beneficial effect of reducing saturated fat on CVD events or mortality, and while some [28, 58, 105], though not all [38, 69], of these studies resulted in reduced CVD risk, it is important to note that these diets replaced saturated fat with polyunsaturated fat. Clinical trials in which replacement of saturated fat occurs in the context of reduced total fat and increased carbohydrate have generally not been associated with improvements in CVD [14, 23]. Recently, the Women's Health Initiative showed no benefit on CVD of reducing total fat from $37 \%$ to $29 \%$ in a cohort of 48,000 post-menopausal women [45]. In the Women's Health Initiative, saturated fat was reduced from 12.4 to $9.5 \%$, polyunsaturated fat was reduced by $1.5 \%$ and dietary carbohydrate was increased by $\sim 8 \%$. A number of large prospective epidemiological studies have not shown a relationship of saturated fat with CVD [8, 46, 47]. In the Nurses' Health Study, polyunsaturated fats and trans fats from industrial sources were identified as being inversely and positively, respectively, associated with increased CHD risk [46, 80]. Notably, the polyunsaturated fat:saturated fat $(\mathrm{P}: \mathrm{S})$ ratio appeared to be strongly and inversely associated with $\mathrm{CHD}$ risk, such that $\mathrm{P}: \mathrm{S}$ ratios $\geq 0.49$ were associated with decreased CHD events[8]. This finding is in line with the data from the clinical trials cited above in which the benefit of reducing saturated fat occurred in the context of diets that were high in polyunsaturated fat [28, $58,105]$. There are also several studies, which have cited inverse associations of dietary saturated fat with CVD. In particular, a handful of studies [40, 51, 52], though not all [43], have suggested that saturated fat intake is associated with decreased risk of ischemic or hemorrhagic stroke. In a study in post-menopausal women, saturated fat was associated with decreased progression of coronary atherosclerosis and dietary carbohydrate was associated with increased progression of the disease [72]. Overall, the data from clinical trials and epidemiology do not support an independent role for saturated fat in the determination of CVD risk. The P:S ratio in the diet appears to be the factor most strongly associated with reduced risk. The main effect of saturated fat intake on CVD risk is thought to be mediated by elevation of LDL-C [66]. Numerous animal and cellular studies have shown that saturated fat raises LDL-C, in part via suppressing LDL receptor activity. Replacement of saturated fat with polyunsaturated fat has been shown to reduce LDL-C [44]. Further, the ability of saturated fat to raise LDL-C may depend on a polyunsaturated fat content below a threshold level ( $\sim 5 \%$ of energy) [114]. Dietary carbohydrate can also modulate the effect of saturated fat on lipid and lipoprotein profiles. Dietary carbohydrate increases plasma triglyceride concentrations, reduces HDL-C and increases concentrations of small, dense LDL-the subclass of LDL that is considered to be more atherogenic-by increasing hepatic triglycerides, which drives the secretion of large, triglyceride-enriched particles [57]. Replacement of saturated fat with carbohydrate results in reductions in both total cholesterol and HDL-C, with no effects on the ratio of total cholesterol to HDL-C [67]. Recently, it was demonstrated that in the context of lower carbohydrate diets (26\% of total energy), lower versus higher levels of dietary saturated fat had no effect on small, dense LDL concentrations [56]. However, the higher concentrations of saturated fat were associated with increases in larger LDL particles, thereby resulting in no change in plasma levels of LDL-C, in contrast to the reductions observed with the lower carbohydrate, low-saturated fat diet. Saturated fat may also influence CVD risk through lipid-independent mechanisms, including effects on lowering insulin sensitivity [26, 89, 107], increasing 
thrombosis [13], increasing inflammatory markers [13, 16], compromising vascular function [77] and raising blood pressure [86]. However, the evidence relating saturated fat and the aforementioned risk factors remains inconclusive and will require further investigation. In the next section, the effects of dairy foods on non-lipid CVD risk are discussed.

\section{Effects of dairy foods on non-lipid risk factors for CVD}

Studies describing the association between dairy product intake and the risk of CVD have been inconsistent. In large epidemiological studies, consumption of high-fat dairy products has been associated with an increase in CVD risk, while intake of low-fat dairy foods has not [47]. On the other hand, a recent survey of publications available on this topic suggested that a high consumption of any type of milk versus a low consumption found no association with an increased risk of CVD [34]. This apparent lack of association between dairy consumption and CVD risk in many studies may appear as being counterintuitive because dairy products contribute significantly to intake of saturated fatty acids, a key LDL-C-raising factor. Yet, investigators are just beginning to unravel and appreciate the complexity of the dairy food matrix and its effects on several other CVD risk factors. At the same time, there is a growing recognition of the contribution of risk factors unrelated to LDL but nonetheless contributing to the pathophysiology of CVD. The following section provides an overview of the effects of dairy foods per se and of their individual components on non-lipid CVD risk factors such as blood pressure, inflammation, insulin resistance and type 2 diabetes, obesity and the metabolic syndrome.

\section{Dairy and blood pressure}

The association between intake of dairy products, calcium, and vitamin $\mathrm{D}$ and the risk of developing hypertension has been extensively investigated. In a prospective cohort of 28,886 US women aged $\geq 45$ years followed over a period of 10 years, a high intake of low-fat dairy products (highest vs. lowest quintile) was associated with a significant $11 \%$ reduction in the risk of developing hypertension [111]. Interestingly, this reduction in risk was also significant across quintiles of dietary calcium and dietary vitamin D, but was not significant across quintiles of calcium or vitamin $\mathrm{D}$ supplements. The positive association between intake of low-fat dairy products and reduced hypertension was significantly attenuated after adjustment for dietary calcium but not after adjustment for vitamin D. Finally, intake of high fat dairy products showed no association with the risk of hypertension in multivariate analysis. This large study in middle-aged and older women emphasized the notion that high fat and low-fat dairy products may not similarly affect blood pressure and, hence, the risk of CVD. Perhaps one of the most acknowledged studies on the association between dairy foods and blood pressure is the multicenter Dietary Approach to Stop Hypertension (DASH) study [5]. In the DASH study, the diet rich in fruits and vegetables and lowfat dairy products reduced systolic blood pressure by $5 \mathrm{mmHg}$ more and diastolic pressure by $3.0 \mathrm{mmHg}$ more than the control diet. About $50 \%$ of the magnitude in these reductions could be ascribed to the dairy foods per se in the diet. It has been estimated that a population-wide reduction in systolic or diastolic blood pressure with the magnitude observed with the DASH diet would reduce incidence of CHD by approximately $15 \%$ and stroke by approximately $27 \%$ [5]. Calcium is thought to be one of the main nutrients responsible for the impact of dairy products on blood pressure [63]. Other minerals such as magnesium and potassium may also regulate blood pressure, but their individual contributions have been difficult to isolate and quantify because they most frequently occur in foods that are also rich in calcium [88]. Both casein and whey proteins are a rich source of specific bioactive peptides that have been shown to have an angiotensin-I-converting enzyme inhibitory effect, a key process in blood pressure control [36]. Studies have also suggested that certain peptides derived from milk proteins may modulate endothelin-1 release by endothelial cells, thereby partly explaining the anti-hypertensive effect of milk proteins [61].

\section{Dairy and inflammation}

Inflammation and oxidative stress are being increasingly recognized as key etiological factors in the development of atherosclerosis and subsequent CVD. A recent study showed that tumor necrosis factor- $\alpha$, interleukin- 6 and monocyte chemoattractant protein- 1 gene expression were markedly decreased in the adipose tissue of ap2-agouti mice fed a high calcium or a high dairy diet, with a corresponding diet-induced increase in adiponectin expression compared with the basal diet [117]. Consistent with these findings, 24 weeks of feeding a high-dairy eucaloric diet and hypocaloric diet in overweight men and women led to a clinically meaningful reduction in plasma C-reactive protein (11 and 29\%, respectively) and to a reciprocal increase in plasma adiponectin concentrations ( 8 and $18 \%$, respectively) [117]. These data suggested that dietary components including calcium and or its unique proteins, the peptides they release, the phospholipids associated with milk fat or the stimulation of HDL by lipids themselves, may suppress adipose tissue oxidative and inflammatory stress. They also emphasized that dairy foods may beneficially alter circulating C-reactive protein and adiponectin 
levels independently of changes in body weight. The extent to which these mechanisms per se may contribute to apparent cardioprotective properties of dairy foods on the development of CVD remains to be more thoroughly demonstrated.

\section{Dairy and type 2 diabetes}

Observational studies show a relatively consistent association between low vitamin D status, or low calcium or dairy intake and prevalent type 2 diabetes. A recent review of published studies indicated that the prevalence of type 2 diabetes was $64 \%$ lower among non-blacks for highest versus lowest 25-hydroxyvitamin D intake [83]. Inverse associations of vitamin D and calcium intake with type 2 diabetes have also been observed. Specifically, highest versus lowest combined vitamin D and calcium intake has been associated with an $18 \%$ reduction in type 2 diabetes, while highest versus lowest dairy intake may reduce the risk of type 2 diabetes by 14\% [83]. The available literature suggests that the reduction in the risk of type 2 diabetes associated with combined vitamin D and calcium supplementation may be significant only in populations at high risk such as those with glucose intolerance. However, it is stressed that the available evidence relating dairy foods, calcium and vitamin $\mathrm{D}$ to type 2 diabetes is limited because most observational studies were cross-sectional and did not adjust for important confounders, while intervention studies were generally short in duration and had limited statistical power due to small sample size [26, 89, 107]. Thus, it is generally agreed that more data are required, particularly from controlled clinical studies, to quantify the efficacy of dairy products in modulating the risk of type 2 diabetes.

Dairy and obesity/metabolic syndrome

The replacement of starchy carbohydrates with protein from lean meat and low-fat dairy ingredients has been suggested to enhance satiety, thereby facilitating weight control [10]. Dairy calcium per se is thought to promote weight loss [116], although the mechanism of action remains unclear. The metabolic syndrome has recently emerged as a clinical concept with important implications in terms of CVD risk management. The prevalence of the metabolic syndrome has been estimated to be around $25 \%$ in industrialized countries, and figures increase with age [37]. Epidemiological studies have shown that patients with the metabolic syndrome have a 2-5-fold greater risk of CVD than metabolic syndrome-free individuals [30]. In many studies, dairy consumption has been inversely associated with the occurrence of one or several facets of the metabolic syndrome. In the CARDIA study that involved 3,157 adults aged 18-30 years, consumption of $\geq 5$ servings/day of dairy products versus $<1.5$ servings/day was associated with a $70 \%$ reduction in the risk of having the metabolic syndrome over a period 10 years [82]. However, this has not been a consistent finding. In an elderly Dutch population, higher dairy consumption has not been associated with lower weight or with a more favorable profile of risk factors associated with the metabolic syndrome, except for a modest association with lower blood pressure [94].

\section{Dairy products as essential contributors of micronutrients in reference food patterns: lessons from elderly people for the entire population}

The intake of common liquid milk has declined or stagnated over the last decade, especially in Europe and North America [49, 50]. Consumers, but also nutritionists, tend to forget that milk contains a wide variety of important nutrients such as protein, calcium, zinc and vitamins B2, B12 and D. This implies that reducing dairy consumption as a means to lower saturated fat intake could create a number of nutritional issues in populations. The most systematic examination of this issue has been pursued in the elderly, though the results are important for all ages. In the current daily food pattern of older adults in The Netherlands and other European countries, it seems hard to replace dairy by other products without risk for inadequate intakes of some of these nutrients.

Micronutrient contribution of dairy products to daily food patterns

From the third Dutch National Food Consumption Survey (1998) [110], the contribution of milk (products) and cheese to daily intake of selected nutrients of Dutch age groups was calculated, allowing comparisons between age groups. Table 1 shows the comparison between the total population and the age category above 65 years. Evident in these data are the large contributions of dairy products to intake of calcium (69-75\%), vitamins B2 (46-50\%) and B12 (30-37\%), protein $(\sim 25 \%)$ and zinc ( $\sim 25 \%)$. Lower, but still significant contributions can be noted for dietary intake of magnesium (17-18\%), vitamins B6 (10-14\%), B1 (10-11\%) and B11 (folic acid) (6-9\%), retinol (7-8\%), vitamin D (7-9\%) and selenium (14-17\%). Contributions to the intake of energy, fat and saturated fat were $15-16 \%$, $\sim 18 \%$ and $27-29 \%$, respectively. A more recent intake assessment on these nutrients for younger adults (1930 years) was reported in 2003 [48]. From Table 1 it can be concluded that nutrient contributions through dairy intake in The Netherlands are rather similar for younger adults and adults aged above 65 years. Such a similarity is 
Table 1 Contribution (\%) of dairy products to the daily intake of energy, macro- and micronutrients; data derived from Dutch National Food Consumption Surveys (DNFCS) in 1998 and 2003

\begin{tabular}{|c|c|c|c|c|c|c|c|c|}
\hline \multirow[t]{3}{*}{ Energy and nutrients } & \multicolumn{2}{|c|}{$\begin{array}{l}\text { DNFCS } 1998 \\
\text { Total population }(n=5,958)\end{array}$} & \multicolumn{4}{|c|}{$\begin{array}{l}\text { DNFCS } 1998 \\
\text { Older adults }(65+)\end{array}$} & \multicolumn{2}{|c|}{$\begin{array}{l}\text { DNFCS } 2003 \\
\text { Young adults (19-30) }\end{array}$} \\
\hline & \multirow[b]{2}{*}{$\begin{array}{l}\text { Milk } \\
\text { (products) }\end{array}$} & \multirow[b]{2}{*}{ Cheese } & \multicolumn{2}{|l|}{$\begin{array}{l}\text { Men } \\
(n=185)\end{array}$} & \multicolumn{2}{|l|}{$\begin{array}{l}\text { Women } \\
(n=236)\end{array}$} & \multirow{2}{*}{$\begin{array}{l}\text { Men } \\
(n=352) \\
\text { All dairy pr }\end{array}$} & \multirow{2}{*}{$\begin{array}{l}\text { Women } \\
(n=398) \\
\text { ucts }\end{array}$} \\
\hline & & & $\begin{array}{l}\text { Milk } \\
\text { (products) }\end{array}$ & Cheese & Milk products & Cheese & & \\
\hline Energy & 11.1 & 4.5 & 10.3 & 4.7 & 11.9 & 4.6 & 13.9 & 15.3 \\
\hline Protein & 17.8 & 8.3 & 16.7 & 8.8 & 19.4 & 8.4 & 24.1 & 26.5 \\
\hline Fat & 9.1 & 8.9 & 9.7 & 8.8 & 9.2 & 8.6 & 17.6 & 18.8 \\
\hline Saturated fat & 14.9 & 14.0 & 13.5 & 13.5 & 14.0 & 13.1 & 30.4 & 31.4 \\
\hline Calcium & 47.7 & 21.1 & 45.8 & 23.6 & 54.8 & 20.2 & 65.6 & 62.6 \\
\hline Magnesium & 15.0 & 2.6 & 14.2 & 2.7 & 15.7 & 2.6 & 15.1 & 17.0 \\
\hline Zinc & 15.6 & 9.7 & 14.8 & 10.0 & 16.3 & 9.2 & 24.8 & 26.7 \\
\hline Selenium & 10.5 & 6.9 & 9.3 & 5.4 & 11.0 & 5.5 & 12.5 & 13.9 \\
\hline Retinol & 8.0 & 8.2 & 6.8 & 6.7 & 7.8 & 7.4 & 14.6 & 15.5 \\
\hline Vitamin D & 5.1 & 4.1 & 3.9 & 3.2 & 4.4 & 3.5 & 9.2 & 10.2 \\
\hline Vitamin $B_{1}$ & 10.0 & 0.7 & 9.0 & 0.7 & 10.4 & 0.7 & 12.7 & 13.0 \\
\hline Vitamin $B_{2}$ & 45.5 & 3.7 & 42.8 & 3.7 & 47.1 & 3.4 & 45.1 & 47.7 \\
\hline Vitamin $\mathrm{B}_{6}$ & 9.0 & 1.1 & 13.0 & 1.1 & 9.8 & 1.0 & 10.1 & 12.0 \\
\hline Vitamin $\mathrm{B}_{11}$ & 7.9 & 1.1 & 6.5 & 0.1 & 8.0 & 0.1 & 11.1 & 13.5 \\
\hline Vitamin $\mathrm{B}_{12}$ & 34.7 & 2.4 & 28.0 & 2.0 & 33.9 & 2.2 & 33.5 & 36.7 \\
\hline
\end{tabular}

The 1998 DNFCS data were based on records for two sequential days of food items noted in a diary; the 2003 data were based on computerassisted 24-h diet recall interviews by trained dieticians on two independent days. The 1998 data for vitamins $\mathrm{B}_{11}$ and $\mathrm{B}_{12}$ were calculated by the authors

also present in current recommendations on food based dietary guidelines where daily intakes of $450-650 \mathrm{~mL}$ and 30-20 g for milk (products) and cheese, respectively, are recommended for each of the three age categories of 1950, 50-70 and over 70 years. These food-based dietary guidelines aim to promote balanced food and nutrient intake, whereby saturated fat content is one of the criteria used to classify foods as "preferred foods." The SENECA survey on nutrition and the elderly has shown that dairy intakes may differ considerably between different regions in Europe [97]. Potential concerns were identified with respect to dietary intake of vitamins $\mathrm{D}$ and B12, but also in relation to, respectively, insufficient sun exposure/skin synthesis and reduced absorption efficiency [42]. Together with calcium, these nutrients appear to have the highest priority in terms of multiple health outcomes for the elderly population, and more in particular to prevention of osteoporotic fractures [18, 19, 27, 31, 96]. The B-vitamins (B6, B11 and B12) have also been associated with cognitive functioning in the elderly, yet available evidence so far does not allow for firm conclusions due to heterogeneity in study designs and methods applied [85]. Milk products are good carriers for enrichment with vitamins D, B11 and B12 $[32,53,79]$.
For the diet of the fragile elderly, other deficienciessuch as for protein, vitamins B1, B2 and B11-are mainly due to inadequate food intake. As loss of body weight or skeletal muscle mass is common in older persons, inadequate intake of protein and energy may result in clinically relevant reductions in strength, exercise capacity and mobility [102].

Dietary patterns versus food items as predictors of survival in the elderly population

Diet and lifestyle influence morbidity and mortality during the course of life [9]. Ten-year mortality from all causes, or specifically from CVD or cancer, has been investigated in 1,507 apparently healthy men and 832 women, aged 7090 years in 11 European countries. In this so-called HALEproject (Healthy ageing: a longitudinal study in Europe), adherence to a defined Mediterranean diet and healthful lifestyle (moderate alcohol use, physical activity and nonsmoking) was associated with a $>50 \%$ lower rate of allcauses and cause-specific mortality [54]. Attempts have been made to assess the predictive value for survival of Mediterranean diet scores in relation to intake of milk (products) in northern versus southern European countries. 
Hazard ratios were different for men and women, and were also dependent on the cut-off values chosen for intake. More beneficial hazard ratios were found when the optimal intake of milk and milk products (excluding butter) was defined as the intake between the P25 and P75 percentile, rather than above or below the median intake (P50). The inconsistencies could not be explained by variations in intake per study site. The P25-P75 cut-off values for men and women were, respectively, 144-474 g/day and 159$465 \mathrm{~g} /$ day [103]. The HALE population was also investigated for the association of total cholesterol, HDL, LDL-C and VLDL-C and 10-year mortality from CVD and all causes. During follow-up, 302 deaths were due to CVD. From the assessed lipid fractions, only a significant inverse association was found between HDL-C and cardiovascular and all-cause mortality; the highest tertile had a significant lower risk of mortality from CVD (HR: 0.72, 95\% CI: 0.54-475 0.95) and all causes (HR: 0.80, 95\% CI: $0.66-$ 0.96) compared with the lowest tertile. These associations remained significant after adjustments for gender, age, education, BMI, smoking, study centre and LDL-C and VLDL-C [55].

\section{Conclusion}

The dairy sector has made continuous advancement over the years, and today there is a wide variety of milks and dairy products readily available to the consumer. The important contributions of these products in meeting human dietary requirements for energy, high quality protein, and several key minerals and vitamins are well documented, though the nutritional importance of dairy fats is often less well understood. In particular, there has been a general perception that a food containing saturated fat is unlikely to be beneficial to health. The purpose of this review and the conference that preceded its compilation was, therefore, to provide an overview and reappraisal of the available scientific evidence examining the impact of dairy foods on CVD risk. Dairy products contribute to the saturated fatty acid composition of the diet. Nonetheless, a systematic review of prospective cohort studies, and the disparities among them, indicated that there is no clear evidence that dairy food consumption is consistently associated with a higher risk of CVD. Of the major types of dairy food, limited evidence to date indicates that cheese appears most likely to be associated with reduced CVD risk. This may reflect the diminished LDL-raising effect of eating cheese compared with the consumption of similar amounts of fat from butter or milk. Much investigation of the effects of other fermented dairy foods has failed to show unequivocally a cholesterol-lowering effect. Furthermore, whereas saturated fats in general are often considered to raise LDL-
$\mathrm{C}$, it is important to note that not all saturated fatty acids in milk fat do so, with 18:0 and very short-chain fatty acids being neutral in terms of effects on LDL-C. Although it remains clear that high $\mathrm{LDL}-\mathrm{C}$ levels are an indication of CVD risk, low levels of HDL-C are also strongly related to CVD risk, and milk fat has been shown to increase plasma HDL-C levels. This, along with emerging evidence of the importance of small dense LDL as a CVD risk factor, and the evidence that levels of these particles are not influenced by saturated fat, warrants further investigation in assigning the overall health implications of dairy food consumption. Whereas the impact of dairy foods on blood pressure is almost beyond debate, their effects on body weight and other non-lipid risk factors need to be further substantiated. Nevertheless, the purported inverse association between dairy foods, particularly low-fat dairy products, and incidence of the metabolic syndrome is suggestive of cardiovascular benefits that may go well beyond the effect of dairy fat on blood lipids. The potential impact of dairy foods on inflammation and oxidative stress is also consistent with this hypothesis. These associations may explain why intake of dairy products in most epidemiological studies has not been associated with an increased cardiovascular risk. Although further research is required to better understand the impact of dairy foods on non-lipid risk factors, there is accumulating evidence that a high intake of dairy products, particularly low-fat products, may in fact be beneficial from a heart health perspective. Further recommendations to reduce saturated fat in the diet below current guidelines should be made with caution and in context, because replacement with dietary carbohydrate can result in the increasingly common triad of lipid abnormalitieselevations in triglyceride, and reductions in HDL-C and small, dense LDL-which has been shown to confer increased CVD risk. Furthermore, continued recommendations to reduce milk fat intake may result in inadequate intakes of key nutrients in certain population groups. In summary, despite the contribution of dairy products to the saturated fatty acid intake of the diet, there is no clear evidence that dairy food consumption is consistently associated with a higher risk of CVD. Given the diversity of available dairy foods of widely differing composition and their contribution to nutrient intake within the population, recommendations to reduce dairy food consumption irrespective of the nature of the dairy product should be made with caution.

Acknowledgments This review reflects the presentations and outcome of the meeting "Scientific Update on Dairy Fats and CVD," which was held on 25 June 2008 in Reading (UK). The event was hosted by the University of Reading (UK) and organized and facilitated by the International Dairy Federation's Standing Committee on Nutrition and Health. The opinions expressed herein are those of the authors. 
Conflict of interest For those authors from academic institutions, the expenses related to their participation in the conference in Reading (UK) were covered by the organizing committee. None of the authors declares any conflict of interest with providing their solely scientific input to the review.

Open Access This article is distributed under the terms of the Creative Commons Attribution Noncommercial License which permits any noncommercial use, distribution, and reproduction in any medium, provided the original author(s) and source are credited.

\section{References}

1. Agerholm-Larsen L, Bell ML, Grunwald GK, Astrup A (2000) The effect of a probiotic milk product on plasma cholesterol: a meta-analysis of short-term intervention studies. Eur J Clin Nutr 54:856-860

2. Al-Delaimy WK, Rimm E, Willett W, Stampfer MJ, Hu FB (2003) A prospective study of calcium intake from diet and supplements and risk of ischaemic heart disease among men. Am J Clin Nutr 77:814-818

3. Allender PS, Cutler JA, Follmann D, Cappuccio F, Pryer J, Elliott P (1996) Dietary calcium and blood pressure: a metaanalysis of randomized clinical trials. Ann Intern Med 124:825831

4. American Heart Association Nutrition Committee, Lichtenstein AH, Appel LJ, Brands M, Carnethon M, Daniels S, Franch HA (2006) Diet and lifestyle recommendations revision 2006: a scientific statement from the American Heart Association Nutrition Committee. Circulation 114:82-96 Erratum in: Circulation (2006) 114(23):e629; Circulation (2006) 114(1):e27

5. Appel LJ, Moore TJ, Obarzanek E, Vollmer WM, Svetkey LP, Sacks FM (1997) A clinical trial of the effects of dietary patterns on blood pressure. DASH Collaborative Research Group. N Engl J Med 336:1117-1124

6. Argraves KM, Argraves WS (2007) HDL serves as a S1P signaling platform mediating a multitude of cardiovascular effects. J Lipid Res 48:2325-2333

7. Artaud-Wild SA, Connor SL, Sexton G, Connor WE (1993) Differences in coronary mortality can be explained by differences in cholesterol and saturated fat intake in 40 countries, but not in France and Finland. Circulation 88:2771-2779

8. Ascherio A, Rimm EB, Giovannucci EL, Spiegelman D, Stampfer M, Willett WC (1996) Dietary fat and risk of coronary heart disease in men: cohort follow up study in the United States. Br Med J 313:84-90

9. Ashwell M, Lambert JP, Alles MS, Branca F, Bucchini L, Brzozowska A (2008) How we will produce the evidence-based EURRECA toolkit to support nutrition and food policy. Eur J Nutr 47(Suppl 1):2-16

10. Astrup A (2006) How to maintain a healthy body weight. Int J Vitam Nutr Res 76:208-215

11. Atzmon G, Gabriely I, Greiner W, Davidson D, Schechter C, Barzilai N (2002) Plasma HDL levels highly correlate with cognitive function in exceptional longevity. J Gerontol A Biol Sci Med Sci 57:M712-M715

12. Atzmon G, Schechter C, Greiner W, Davidson D, Rennert G, Barzilai N (2004) Clinical phenotype of families with longevity. J Am Geriatr Soc 52:274-277

13. Baer DJ, Judd JT, Clevidence BA, Tracy RP (2004) Dietary fatty acids affect plasma markers of inflammation in healthy men fed controlled diets: a randomized crossover study. Am J Clin Nutr 79:969-973
14. Ball KP, Hanington E, McAllen P (1965) Low fat diet in myocardial infarction: a controlled trial. Lancet 2(7411):501504

15. Barzilai N, Atzmon G, Schechter C, Schaefer EJ, Cupples AL, Lipton R (2003) Unique lipoprotein phenotype and genotype associated with exceptional longevity. JAMA 290:2030-2040

16. Bellido C, Lopez-Miranda J, Blanco-Colio LM (2004) Butter and walnuts, but not olive oil, elicit postprandial activation of nuclear transcription factor kappaB in peripheral blood mononuclear cells from healthy men. Am J Clin Nutr 80:1487-1491

17. Biong AS, Miller H, Seljeflot I, Veierod MB, Pedersen JI (2004) A comparison of the effects of cheese and butter on serum lipids, haemostatic variables and homocysteine. Br J Nutr 92:791-797

18. Bischoff-Ferrari HA, Giovannucci E, Willett WC, Dietrich T, Dawson-Hughes B (2006) Estimation of optimal serum concentrations of 25-hydroxyvitamin $\mathrm{D}$ for multiple health outcomes. Am J Clin Nutr 84:18-28

19. Boonen S, Lips P, Bouillon R, Bischoff-Ferrari HA, Vanderschueren D, Haentjens P (2007) Need for additional calcium to reduce the risk of hip fracture with vitamin $\mathrm{D}$ supplementation: evidence from a comparative metaanalysis of randomized controlled trials. J Clin Endocrinol Metab 92:1415-1423

20. Bostick R, Kushi LH, Wu Y, Meyer KA, Sellers TA, Folsom AR (1999) Relation of calcium, vitamin D and dairy food intake to ischaemic heart disease mortality among postmenopausal women. Am J Epidemiol 149:151-161

21. British Nutrition Foundation. Heart disease and stroke (cardiovascular disease). 2004 http://www.nutrition.org.uk/home.asp? siteId $=43$ \&sectionId $=404 \&$ subSectionId=321 \& parentSection= 299\&which $=1$ [accessed 25 August 2008]

22. Bucher HC, Cook RJ, Guyatt GH, Lang JD, Cook DJ, Hatala R (1996) Effects of dietary calcium supplementation on blood pressure. A meta-analysis of randomised controlled trials. JAMA 275:1016-1022

23. Burr ML, Fehily AM, Gilbert JF (1989) Effects of changes in fat, fish, and fibre intakes on death and myocardial reinfarction: diet and reinfarction trial (DART). Lancet 2:757-761

24. Canturk NZ, Canturk Z, Oka YE, Yirmibesoglu O, Eraldemir B (2002) Risk of nosocomial infections and effects of total cholesterol, HDL cholesterol in surgical patients. Clin Nutr 21:431-436

25. Chardigny J-M, Destaillats F, Malpuech-Brugere C, Moulin J, Bauman DE, Lock AL (2008) Do trans fatty acids from industrially produced sources and from natural sources have the same effect on cardiovascular risk factors in healthy subjects? Results from trans fatty acids collaboration (TRANSFACT) study. Am J Clin Nutr 87:558-566

26. Christiansen E, Schnider S, Palmvig B, Tauber-Lassen E, Pedersen O (1997) Intake of a diet high in trans monounsaturated fatty acids or saturated fatty acids. Effects on postprandial insulinemia and glycemia in obese patients with NIDDM. Diabetes Care 20:881-887

27. Clarke R, Sherliker P, Hin H, Nexo E, Hvas AM, Schneede J (2007) Detection of vitamin B12 deficiency in older people by measuring vitamin B12 or the active fraction of vitamin B12, holotranscobalamin. Clin Chem 53:963-970

28. Dayton S, Pearce M, Hashimoto S (1969) A controlled clinical trial of a diet high in unsaturated fat in preventing complications of atherosclerosis. Circulation 40(Suppl II):II-1-II-63

29. Department of Health and Ageing (2003) Dietary guidelines for Australians: a guide to healthy eating. Australian National Health and Medical Research Council. http://www.nhmrc.gov.au/ publications/synopses/dietsyn.htm [accessed 25 August 2008]

30. Desroches S, Lamarche B (2007) The evolving definitions and increasing prevalence of the metabolic syndrome. Appl Physiol Nutr Metab 32:23-32 
31. Dhonukshe-Rutten RAM, Pluijm SMF, de Groot CPGM, Lips P, Smit JH, van Staveren WA (2005) Homocysteine and vitamin B12 status relate to bone turnover markers, broadband ultrasound attenuation, and fractures in healthy elderly people. J Bone Miner Res 20:921-929

32. Dhonukshe-Rutten RAM, van Zutphen M, de Groot CPGM, Eussen SJPM, Blom HJ, van Staveren WA (2005) Effect of supplementation with cobalamin carried either by a milk product or a capsule in mildly cobalamin-deficient elderly Dutch persons. Am J Clin Nutr 82:568-574

33. Elwood PC, Pickering JE, Fehily AM, Hughes J, Ness AR (2004) Milk drinking, ischaemic heart disease and ischaemic stroke I: evidence from Caerphilly cohort. Eur J Clin Nutr 58:711-717

34. Elwood PC, Pickering JE, Hughes J, Fehily AM, Ness AR (2004) Milk drinking, ischaemic heart disease and ischaemic stroke II. Evidence from cohort studies. Eur J Clin Nutr 58: $718-724$

35. Feingold KR, Funk JL, Moser AH, Shigenaga JK, Rapp JH, Grunfeld C (1995) Role for circulating lipoproteins in protection from endotoxin toxicity. Infect Immun 63:2041-2046

36. FitzGerald RJ, Murray BA, Walsh DJ (2004) Hypotensive peptides from milk proteins. J Nutr 134:980S-988S

37. Ford ES, Giles WH, Dietz WH (2002) Prevalence of the metabolic syndrome among US adults: findings from the third National Health and Nutrition Examination Survey. JAMA 287:356-359

38. Frantz ID Jr, Dawson EA, Ashman PL (1989) Test of effect of lipid lowering by diet on cardiovascular risk. The Minnesota Coronary Survey. Arteriosclerosis 9:129-135

39. Gartside PS, Wang P, Glueck CJ (1998) Prospective assessment of coronary heart disease risk factors: the NHANES I epidemiologic follow-up study (MHEFS) 16-year follow-up. J Am Coll Nutr 17:263-269

40. Gillman MW, Cupples LA, Millen BE, Ellison RC, Wolf PA (1997) Inverse association of dietary fat with development of ischemic stroke in men. JAMA 278:2145-2150

41. Gordon T (1988) The diet-heart idea: outline of a history. Am J Epidemiol 127:220-225

42. Groot de CPMG, Verheijden MW, de Henauw S, Schroll M, van Staveren WA, for the SENECA Investigators (2004) Lifestyle, nutritional status, health, and mortality in elderly people across Europe: A review of the longitudinal results of the SENECA study. J Gerontol A Biol Sci Med Sci 59:1277-1284

43. He K, Merchant A, Rimm EB (2003) Dietary fat intake and risk of stroke in male US healthcare professionals: 14 year prospective cohort study. Br Med J 327:777-782

44. Hodson L, Skeaff CM, Chisholm WA (2001) The effect of replacing dietary saturated fat with polyunsaturated or monounsaturated fat on plasma lipids in free-living young adults. Eur J Clin Nutr 55:908-915

45. Howard BV, Van Horn L, Hsia J (2006) Low-fat dietary pattern and risk of cardiovascular disease: the Women's Health Initiative Randomized Controlled Dietary Modification Trial. JAMA 295:655-666

46. Hu FB, Stampfer MJ, Manson JE (1997) Dietary fat intake and the risk of coronary heart disease in women. N Engl J Med 337:1491-1499

47. Hu FB, Stampfer MJ, Manson JE, Ascherio A, Colditz GA, Speizer FE (1999) Dietary saturated fats and their food sources in relation to the risk of coronary heart disease in women. Am J Clin Nutr 70:1001-1008

48. Hulshof KFAM, Ocké MC, van Rossum CTM, Buurma-Rethans EJM, Brants HAM, Drijvers JJMM, ter Doest D (2004) Resultaten van de Voedselconsumptiepeiling 2003 (Results of the national food consumption survey 2003) RIVM rapport 350030002/2004 (http://www.rivm.nl/bibliotheek/rapporten/350030002.html) [accessed 25 August 2008]

49. International Dairy Federation (2002) World Dairy Situation Bulletin 378/2002

50. International Dairy Federation (2007) World Dairy Federation Bulletin 423/2007

51. Iso H, Sato S, Kitamura A, Naito Y, Shimamoto T, Komachi Y (2003) Fat and protein intakes and risk of intraparenchymal hemorrhage among middle-aged Japanese. Am J Epidemiol 157:32-39

52. Iso H, Stampfer MJ, Manson JE (2001) Prospective study of fat and protein intake and risk of intraparenchymal hemorrhage in women. Circulation 103:856-863

53. de Jong RJ, Verwei M, West CE, van Vliet T, Siebelink E, van den Berg H (2005) Bioavailability of folic acid from fortified pasteurised and UHT-treated milk in humans. Eur J Clin Nutr 59:906-913

54. Knoops KT, de Groot LC, Kromhout D, Perrin AE, MoreirasVarela O, Menotti A, van Staveren WA (2004) Mediterranean diet, lifestyle factors, and 10-year mortality in elderly European men and women: the HALE project. JAMA 292:1433-1439

55. Knoops KTB, de Groot CPGM, van Staveren WA, Kromhout D (2008) Different cholesterol fractions and 10-year cardiovascular and all-cause mortality in European elderly men and women: The HALE-project (submitted for publication)

56. Krauss RM, Blanche PJ, Rawlings RS, Fernstrom HS, Williams PT (2006) Separate effects of reduced carbohydrate intake and weight loss on atherogenic dyslipidemia. Am J Clin Nutr 83:1025-1031

57. Krauss RM, Siri PW (2004) Metabolic abnormalities: triglyceride and low-density lipoprotein. Endocrinol Metab Clin North Am 33:405-415

58. Leren P (1970) The Oslo diet-heart study. Eleven-year report. Circulation 42:935-942

59. Levels JH, Abraham PR, Van Denende A, Van Deventer SJ (2001) Distribution and kinetics of lipoprotein-bound endotoxin. Infect Immun 69:2821-2828

60. Liuba P, Persson J, Luoma J, Yla-Herttuala S, Pesonen E (2003) Acute infections in children are accompanied by oxidative modification of LDL and decrease of HDL cholesterol, and are followed by thickening of carotid intima-media. Eur Heart $\mathrm{J}$ 24:515-521

61. Maes W, Van Camp J, Vermeirssen V, Hemeryck M, Ketelslegers JM, Schrezenmeir J (2004) Influence of the lactokinin Ala-Leu-Pro-Met-His-Ile-Arg (ALPMHIR) on the release of endothelin-1 by endothelial cells. Regul Pept 118:105-109

62. Mann JI, Appleby PN, Key TJ, Thorogood M (1997) Dietary determinants of ischaemic heart disease in health conscious individuals. Heart 78:450-455

63. McCarron DA, Reusser ME (1999) Finding consensus in the dietary calcium-blood pressure debate. J Am Coll Nutr 18:398S-405S

64. McGee DL, Reed DM, Yano K, Kagan A, Tillotson J (1984) Ten-year incidence of coronary heart disease in the Honolulu Heart Program. Am J Epidemiol 119:667-676

65. Menotti A, Kromhout D, Blackburn H (1999) Food intake patterns and 25-year mortality from coronary heart disease: cross cultural correlations in the Seven Countries Study. Eur J Epidemiol 15:507-515

66. Mensink RP, Katan MB (1992) Effect of dietary fatty acids on serum lipids and lipoproteins. A meta-analysis of 27 trials. Arterioscler Thromb 12:911-919

67. Mensink RP, Zock PL, Kester AD, Katan MB (2003) Effects of dietary fatty acids and carbohydrates on the ratio of serum total to HDL cholesterol and on serum lipids and apolipoproteins: a metaanalysis of 60 controlled trials. Am J Clin Nutr 77:1146-1155 
68. Mensink RP (2005) Effects of stearic acid on plasma lipid and lipoproteins in humans. Lipids 40:1201-1205

69. Morris JN, Ball KP, Antonis A (1968) Controlled trial of soyabean oil in myocardial infarction. Lancet 2(7570):693-699

70. Moss M, Freed D (2003) The cow and the coronary: epidemiology, biochemistry and immunology. Int J Cardiol 87:203-216

71. Motard-Belanger A, Charest A, Grenier G, Paquin P, Chouinard Y, Lemeieux S (2008) Study of the effect of trans fatty acids from ruminants on blood lipids and other risk factors for cardiovascular disease. Am J Clin Nutr 87:593-599

72. Mozaffarian D, Rimm EB, Herrington DM (2004) Dietary fats, carbohydrate, and progression of coronary atherosclerosis in postmenopausal women. Am J Clin Nutr 80:1175-1184

73. Navab M, Ananthramaiah GM, Reddy ST, Van Lenten BJ, Ansell BJ, Fonarow GC (2004) The oxidation hypothesis of atherogenesis: the role of oxidized phospholipids and HDL. J Lipid Res 45:993-1007

74. Ness AR, Davey Smith G, Hart C (2001) Milk, coronary heart disease and mortality. J Epidemiol Community Health 55:379382

75. Nestel P (1999) Saturated and trans fatty acids and coronary heart disease. Eur Heart J 1(Suppl S):S19-S23

76. Nestel PJ, Chronopoulos A, Cehun M (2005) Dairy fat in cheese raises LDL cholesterol less than that in butter in mildly hypercholesterolaemic subjects. Eur J Clin Nutr 50:1059-1063

77. Nicholls SJ, Lundman P, Harmer JA (2006) Consumption of saturated fat impairs the anti-inflammatory properties of highdensity lipoproteins and endothelial function. J Am Coll Cardiol 48:715-720

78. Nissen SE, Tsunoda T, Tuzcu EM, Schoenhagen P, Cooper CJ, Yasin M (2003) Effect of recombinant ApoA-I Milano on coronary atherosclerosis in patients with acute coronary syndromes: a randomized controlled trial. JAMA 290:2292-2300

79. Lamberg-Allardt C (2006) Vitamin D in foods and as supplements. Prog Biophys Mol Biol 92(1):33-38

80. Oh K, Hu FB, Manson JE, Stampfer MJ, Willett WC (2005) Dietary fat intake and risk of coronary heart disease in women: 20 years of follow-up of the nurses' health study. Am J Epidemiol 161:672-679

81. Pajkrt D, Doran JE, Koster F (1996) Antiinflammatory effects of reconstituted high density lipoprotein during human endotoxemia. J Exp Med 184:1601-1608

82. Pereira MA, Jacobs DR Jr, Van Horn L, Slattery ML, Kartashov AI, Ludwig DS (2002) Dairy consumption, obesity, and the insulin resistance syndrome in young adults: the CARDIA Study. JAMA 287:2081-2089

83. Pittas AG, Lau J, Hu FB, Dawson-Hughes B (2007) The role of vitamin $\mathrm{D}$ and calcium in type 2 diabetes. A systematic review and meta-analysis. J Clin Endocrinol Metab 92:2017-2029

84. Rader D (2006) Molecular regulation of HDL metabolism and function: implications for novel therapies. $J$ Clin Invest 116:3090-3100

85. Raman G, Tatsioni A, Chung M, Rosenberg IH, Lau J, Lichtenstein AH (2007) Heterogeneity and lack of good quality studies limit association between folate, vitamins B6 and B12 and cognitive functioning. J Nutr 137:1789-1794

86. Rasmussen BM, Vessby B, Uusitupa M (2006) Effects of dietary saturated, monounsaturated, and n-3 fatty acids on blood pressure in healthy subjects. Am J Clin Nutr 83:221-226

87. Renaud S, de Lorgeril M (1989) Dietary lipids and their relationship to ischaemic heart disease: from epidemiology to prevention. J Intern Med 225:1-8

88. Sacks FM, Willett WC, Smith A, Brown LE, Rosner B, Moore TJ (1998) Effect on blood pressure of potassium, calcium, and magnesium in women with low habitual intake. Hypertension $31: 13-138$
89. Salmeron J, Hu FB, Manson JE (2001) Dietary fat intake and risk of type 2 diabetes in women. Am J Clin Nutr 73:1019-1026

90. Samuelson G, Bratteby L-E, Mohsen R, Vessby B (2001) Dietary fat intake in healthy adolescents: inverse relationships between the estimated intake of saturated fatty acids and serum cholesterol. Br J Nutr 85:333-341

91. Segall JJ (1977) Is milk a coronary health hazard? Br J Prevent Soc Med 31:81-85

92. Shaper AG, Wannamethee G, Walker M (1991) Milk, butter and heart disease. Br Med J 302:785-786

93. Sjogren P, Rosell M, Skoglund-Andersson C, Zdrakovic S, Vessby B, de Faire U (2004) Milk-derived fatty acids are associated with a more favorable LDL particle size distribution in healthy men. J Nutr 34:1729-1735

94. Snijder MB, van Dam RM, Stehouwer CD, Hiddink GJ, Heine RJ, Dekker JM (2008) A prospective study of dairy consumption in relation to changes in metabolic risk factors: the Hoorn Study. Obesity 16:706-709

95. Snowdon DA, Phillips RL, Fraser GE (1984) Meat consumption and fatal ischemic heart disease. Prev Med 13:490-500

96. Stabler SP, Allen RH (2004) Vitamin B12 deficiency as a worldwide problem. Annu Rev Nutr 24:299-326

97. van Staveren WA, de Groot CPMG, Haveman-Nies A (2002) The SENECA study: potentials and problems in relating diet to survival over 10 years. Public Health Nutr 5(6A):901-905

98. St-Onge M-P, Farnworth ER, Jones PJH (2000) Consumption of fermented and nonfermented dairy products: effects on cholesterol concentrations and metabolism. Am J Clin Nutr 71:674681

99. Terasaka N, Wang N, Yvan-Charvet L, Tall AR (2007) HDL protects macrophages from oxidized LDL-induced apoptosis by promoting efflux of 7-ketocholesterol via ABCG1. Proc Natl Acad Sci USA 104:15093-15098

100. Tholstrup T (2006) Dairy products and cardiovascular disease. Curr Opin Lipidol 17:1-10

101. Tholstrup T, Hoy C-E, Andersen LN, Christensen RDK, Sandstrom B (2004) Does fat in milk, butter and cheese affect blood lipids and cholesterol differently? J Am Coll Nutr 23:169-176

102. Thomas DR (2007) Loss of skeletal muscle mass in aging: Examining the relationship of starvation, sarcopenia and cachexia. Clin Nutr 26:389-399

103. Toth PP (2005) High-density lipoprotein as a therapeutic target: clinical evidence and treatment strategies. Am J Cardiol 96:50K-58K discussion $34 \mathrm{~K}-35 \mathrm{~K}$

104. Tricon S, Burdge GC, Jones EL, Russell JJ, El-Khazen S, Moretti E, Hall WL, Gerry AB, Leake DS, Grimble RF, Williams CM, Calder PC, Yaqoob P (2006) Effects of dairy products naturally enriched with cis- 9 , trans- 11 conjugated linoleic acid on the blood lipid profile in healthy middle-aged men. Am J Clin Nutr 83:744-753

105. Turpeinen O, Karvonen MJ, Pekkarinen M, Miettinen M, Elosuo R, Paavilainen E (1979) Dietary prevention of coronary heart disease: the Finnish Mental Hospital Study. Int J Epidemiol 8:99-118

106. Umesawa M, Iso H, Date C, Yamamoto A, Toyoshima H, Wantanabe Y (2006) Dietary intake of calcium in relation to mortality from cardiovascular disease: the JACC study. Stroke 37:20-26

107. Van Dam RM, Willett WC, Rimm EB, Stampfer MJ, Hu FB (2002) Dietary fat and meat intake in relation to risk of type 2 diabetes in men. Diabetes Care 25:417-424

108. Van Der Vijver LPL, Van Der Waal MAE, Weterings KGC, Dekker JM, Schouten EG, Kok F (1992) Calcium intake and 28year cardiovascular and coronary heart disease mortality in Dutch civil servants. Int J Epidemiol 21:36-39 
109. Van Leeuwen HJ, Van Beek AP, Dallinga-Thie GM, Van Strijp JA, Verhoef J, Van Kessel KP (2001) The role of high density lipoprotein in sepsis. Neth J Med 59:102-110

110. Voorlichtingsbureau voor de Voeding (1998) Zo eet Nederland. Resultaten van de Voedselconsumptiepeiling 1997-1998 (Dutch National Food Consumption Survey of 1997-1998) Delft, Netherlands: Voedingscentrum, 1998 (in Dutch)

111. Wang L, ManFneson JE, Buring JE, Lee IM, Sesso HD (2008) Dietary intake of dairy products, calcium, and vitamin $\mathrm{D}$ and the risk of hypertension in middle-aged and older women. Hypertension 51:1073-1079

112. Wang N, Lan D, Chen W, Matsuura F, Tall AR (2004) ATPbinding cassette transporters G1 and G4 mediate cellular cholesterol efflux to high-density lipoproteins. Proc Natl Acad Sci USA 101:9774-9779
113. Wang X, Paigen B (2005) Genetics of variation in HDL cholesterol in humans and mice. Circ Res 96:27-42

114. Wijendran V, Hayes KC (2004) Dietary n-6 and n-3 fatty acid balance and cardiovascular health. Annu Rev Nutr 24:597-615

115. Yu S, Derr J, Etherton TD, Kris-Etherton PM (1995) Plasma cholesterol-predictive equations demonstrate that stearic acid is neutral and monounsaturated fatty acids are hypocholesterolemic. Am J Clin Nutr 61:1129-1139

116. Zemel MB (2005) The role of dairy foods in weight management. J Am Coll Nutr 24(6 Suppl):537S-546S

117. Zemel MB, Sun X (2008) Dietary calcium and dairy products modulate oxidative and inflammatory stress in mice and humans. J Nutr 138:1047-1052 